\title{
MEASUREMENT AND ANALYSIS OF DYNAMIC RIDING BEHAVIOR OF A MOTORCYCLE
}

\author{
Tobiáš M.*, Porteš P..*, Zháňal L.***, Fojtášek J.****
}

\begin{abstract}
A long-term project at the Institute of automotive engineering at FME BUT, aims to analyze a motorcycle's dynamic riding behavior using in-house developed methods, originally intended for cars. A multi-body model of a motorcycle based on the measured parameters of a motorcycle and a system for measuring multiple physical quantities during a test ride were created. The necessary motorcycle parameters were measured using a $3 D$ scanner and through experiments aided by computer technology and CAD software. Presented method is based on connecting measured data during test ride with an inverted multibody model. This enables the processing of data and analysis of measured dynamic states of motorcycle, while the details of output quantities are comparable with outputs from simulation calculations. Presented work has laid a foundation for a follow-up research and development work.
\end{abstract}

Keywords: Motorcycle, Dynamics, Simulation, Measurement, Multi-body.

\section{Introduction}

An in-house developed SADT (System of Automotive Development Tools) is used to support the mechanical design of a vehicle, analysis of its dynamic states (calculated and measured) and optimize kinematic and dynamic characteristics of wheel suspensions as well as vehicle subsystems that affect driving characteristics of a car. Using SADT tools requires a precise mathematical model of studied mechanical system, along with a range of input information gathered during an actual ride. These tools can be applied both before the prototype is created and during fine-tuning of the vehicle's driving characteristics based on test rides as stated at (Research, Vehicle Dynamics, SADT, IAE FME BUT: SADT - System of Automotive Development Tools, 2020). This notion is especially appetizing for those interested in studying motorcycle's dynamic behavior as they are inherently unstable vehicles.

\section{Experimental motorcycle}

For the purposes of this project, a KTM RC 390 motorcycle has been used as shown in Fig. 1. It is a modern, lightweight, sport-touring, single-cylinder motorcycle with a moderate engine size and power. Front wheel is suspended by an upside-down telescopic fork, rear wheel is pivoted on a swingarm with a single shock absorber.

\section{Methods}

From the viewpoint of vehicle dynamics multi-body simulations are very progressive, but results are heavily dependent on the accuracy of the model, fidelity of load conditions, tire models, etc. These characteristics are even more pronounced with motorcycles, whose dynamic riding behavior depends heavily on a rider's motion relative to the vehicle as stated by (Cossalter, 2006). All these shortcomings are

* Ing. Martin Tobiáš: Institute of Automotive Engineering, Brno University of Technology, Technicka 2896/2; 616 69, Brno; CZ, martin.tobias@vut.cz

** Assoc. Prof. Ing. Petr Porteš, PhD.: Institute of Automotive Engineering, Brno University of Technology, Technicka 2896/2; 616 69, Brno; CZ, portes@fme.vutbr.cz

*** Ing. Lubor Zháňal, PhD.: Institute of Automotive Engineering, Brno University of Technology, Technicka 2896/2; 616 69, Brno; CZ, lubor.zhanal@vut.cz

**** Ing. Jan Fojtášek, PhD.: Institute of Automotive Engineering, Brno University of Technology, Technicka 2896/2; 616 69, Brno; CZ, jan.fojtasek@vutbr.cz 
possible to avoid, by compiling reverse multi-body simulations, where all the inputs for the simulation come from measured test ride. This is the core idea behind SADT system, which has been successfully used and proven on two-track vehicles by (Porteš, 2014 and Porteš et al., 2018).

For a study of a dynamic behavior of any land vehicle, the most prized information is arguably forces and their vectors in contact between the tires and a road, which the SADT tools mentioned in the introductory section allow to calculate. Precision of these calculations depends proportionately on accuracy and number of parameters that are measured during a test ride. This method can yield very accurate information independent of the type of road or road conditions, completely bypassing all shortcomings of mathematical tire models.

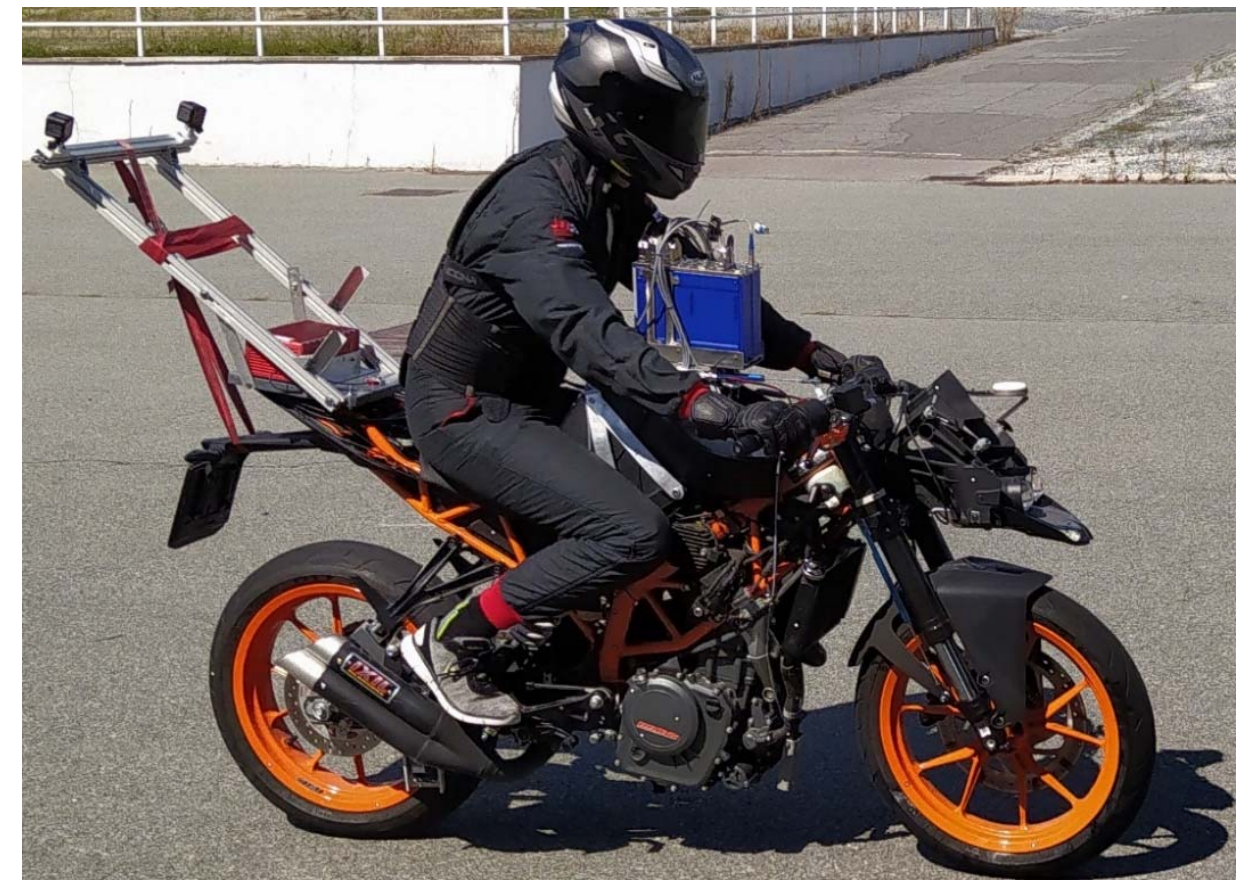

Fig. 1: Experimental motorcycle KTM RC 390 during a test ride.

\subsection{KTM RC 390 parameters}

As stated by (Tobiáš, 2019), to create virtual model, following parameters had to be measured:

- Kinematics, precise location of key points in a determinate coordinate system;

- Center of mass location within this coordinate system, without wheels;

- Moments of inertia along coordinate system axes, without wheels;

- Weights and moments of inertia of wheels.

\section{Kinematics}

To determine the location of key points an in-house 3D scanner GOM Atos Compact Scan 2M was used.

\section{Center of mass location}

To determine the center of mass (CM for short) location, the motorcycle was suspended freely above level ground two times in different positions and scanned. In each scan an intersection of a line normal to the ground with hinge point was found, intersection of these lines gave the CM location.

\section{Moments of inertia of the motorcycle and wheels}

To determine the values of moments of inertia along coordinate system axes, a simple gravity pendulum model was employed. Motorcycle was pivoted along set axes and the swinging motion was measured by a digital gyroscope. This was done multiple times for each axis in order to average-out inaccuracies and to guarantee excellent repeatability. Then by solving slightly modified, but still rather simple mathematical equations of mathematical pendulum and Steiner's theorem a final value for moments of inertia were calculated. 


\subsection{Ride-measuring system}

The heart of the measuring system is IMC CRONOSflex 400 datalogger. Fig. 2 shows a schematic arrangement of sensor used to gather necessary information. Suspension forces were measured directly by strain gauges glued to the piston rods of shock absorbers. Other sensors were mounted on tailor-made brackets, some 3D printed from ABS plastic. Following is the list of main measured physical quantities.

- Location and orientation of motorcycle in space:

- 3 translational coordinates,

o 3 angles (roll $-\mathrm{X}$, pitch $-\mathrm{Y}$, Yaw $-\mathrm{Z}$ );

- Speed and acceleration of the motorcycle:

o 3 translational velocities +3 angular velocities,

o 3 translational accelerations +3 angular accelerations;

- Wheels angular rotation speed;

- Suspension travel, suspension forces;

- Steering angle;

- Roadway position relative to the motorcycle;

- Riders position.

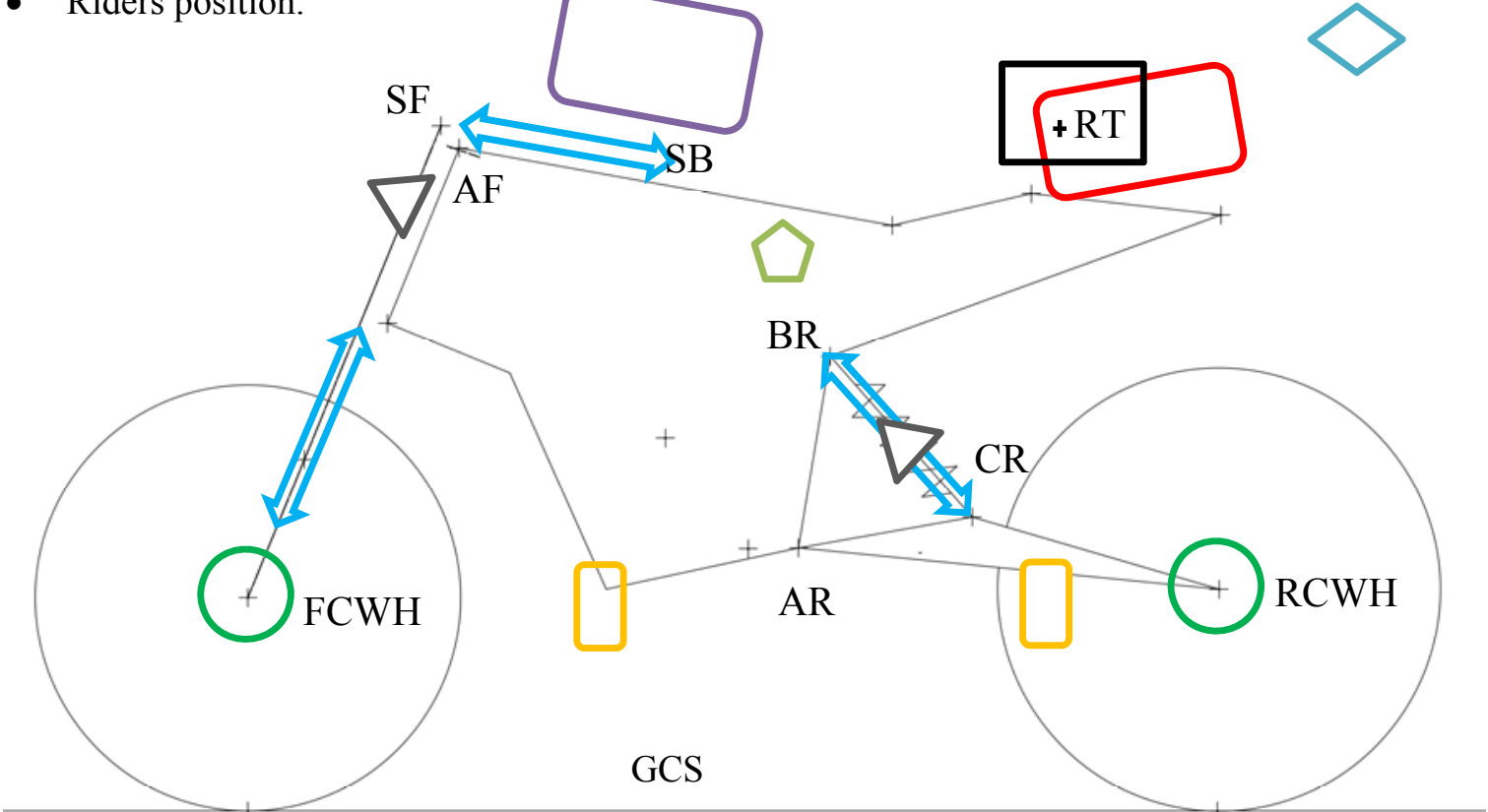

3x Potentiometers - suspension travel, steering angle
2x ABS sensors - wheels rotation
3x LED distance sensors RHS 50-400 - relative roadway position
OxTS RT3002 inertial navigation system - position, speed and acceleration
imc CRONOSflex 400 data acquisition system
strain gauges - suspension forces
2x GoPRO camera - riders' position
OBD II diagnostic connection - throttle position, engine rpm

Fig. 2: Kinematical model, sensors arrangement.

\subsection{Multibody model}

Using the measured parameters, a multi-body model of the experimental motorcycle was created within SADT system and interconnected with the measured data using Telematrix software. The dynamic model of the motorcycle is built on top of the kinematical model and in addition includes elements with known (measured; such as forces acting from spring damper units) and unknown force effects, the magnitude of which is calculated from the movement of the vehicle (tire forces, drive torque or brake moments, chain forces, aerodynamic drag and lift forces, steering torque). See Fig. 2 and Tab. 1 for schematic description. 
Tab. 1: Topology of the dynamical model.

\begin{tabular}{|l|l|c|l|}
\hline \multicolumn{2}{|l|}{ Description of connection } & DOF & Type of joint or constraint \\
\hline GCS & ARM (auxiliary body) to GCS (global coordinate system) & +3 & Translational joint \\
\hline RT & BODY to ARM (auxiliary body) & +3 & Spherical joint \\
\hline AF & FORK to BODY & +1 & Cylindrical (only rotation) \\
\hline AF & TUBE to FORK & +1 & Cylindrical (only translation) \\
\hline FCWH & FWH (front wheel) to TUBE & +1 & Cylindrical (only rotation) \\
\hline AR & RARM (rear arm) to BODY & +1 & Cylindrical (only rotation) \\
\hline RCWH & RWH (rear wheel) to RARM (rear arm) & +1 & Cylindrical (only rotation) \\
\hline CR & RDM (rear damper) to RARM (rear arm) & +1 & Spherical (only one rotation) \\
\hline CR & RPR (rear damper piston rod) to RDM (rear damper) & +1 & Translat. (only one translation) \\
\hline BR & RPR (rear damper piston rod) to BODY & -2 & Constraint - point (x z) \\
\hline SB & SPOT (steering potentiometer) to BODY & +2 & Spherical (only two rotation) \\
\hline SB & SPR (steering pot. piston rod) to SPOT (steering pot.) & +1 & Translat. (only one translation) \\
\hline SF & SPR (steering potentiometer piston rod) to FORK & -3 & Constraint - point (x y z) \\
\hline
\end{tabular}

\section{Measured test ride}

A test ride was realized on a relatively flat concrete surface. It comprised of a rapid acceleration in straight line followed by intensive braking, steady state circular test in both directions and an obstacle course in form of a slalom. Ride measurement system proved to be functional, all the necessary data were collected.

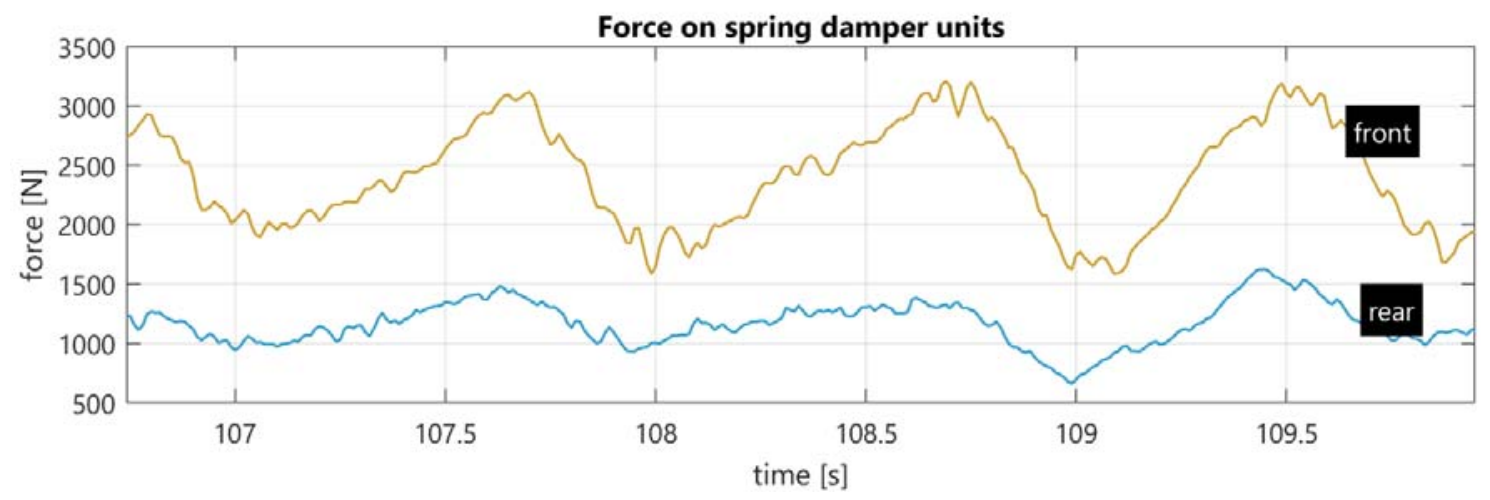

Fig. 3: Example of measured data during a test ride.

\section{Conclusion}

Methods presented in this paper show promise in being able to calculate parameters, which were not directly measured. Despite the satisfactory results from the first stage of testing, both the ride measurement system and virtual dynamic model are currently subject of further development focused mainly on a detailed analysis of the driver's influence in more complex driving contiditions.

\section{Acknowledgement}

The authors gratefully acknowledge funding from the Specific research on BUT FSI-S-20-6267, and also funding from the internal FME BUT program Fund of Science, project name Measuring system of motorcycles dynamic states, Reg. No. FV 20-32.

\section{References}

Cossalter, V. (2006). Motorcycle dynamics (2nd English ed.), Lulu.

Porteš, P. (2014) Utilisation of mathematical vehicle models in analysis of measured data. Habilitation Thesis, Brno University of Technology (in Czech).

Porteš, P., Zháňal L. and Fojtášek, J. (2018) Complex approach to computations and analysis of vehicle dynamics. In Vibroengineering Procedia. Vibroengineering Procedia. Lithuania: JVE International, pp. 132-137. ISSN: 23450533.

Research, Vehicle Dynamics, SADT, IAE FME BUT: SADT - System of Automotive Development Tools. (2020). Institute of Automotive Engineering. Retrieved 15 Sep. 2020, from http://www.iae.fme.vutbr.cz/research-vehicledynamics-sadt- $2 \mathrm{j}$.

Tobiáš, M. (2019) Analysis of dynamic measured states of motorcycles. Diploma Thesis. Brno University of Technology, Faculty of Mechanical Engineering, 68 p., (in Czech). 